\title{
RIBEIRA CONECTADA: CIDADE INTELIGENTE E CONSERVAÇÃO INTEGRADA EM PROL DE UMA SUSTENTABILIDADE SOCIOAMBIENTAL
}

\section{RIBEIRA CONECTADA: CIUDAD INTELIGENTE Y CONSERVACIÓN INTEGRADA EN FAVOR DE UNA SOSTENIBILIDAD SOCIOAMBIENTAL}

\section{CONNECTED RIBEIRA: SMART CITY AND INTEGRATED CONSERVATION FOR SOCIO. ENVIRONMENTAL SUSTAINABILITY}

\section{SILVA, HEITOR DE ANDRADE}

Professor do Departamento de Arquitetura, do Programa de Pós-Graduação em Arquitetura e Urbanismo e Programa de Pós-Graduação em Arquitetura, Projeto e Meio Ambiente da Universidade Federal do Rio Grande do Norte | heitor.andrade@ufrn.abea.arq.br

\section{MELO, REYMARD SÁVIO SAMPAIO}

Professor do Departamento de Engenharia Civil e do Programa de Pós-Graduação em Engenharia Civil da Universidade Federal do Rio Grande do Norte | reymardsavio@gmail.com

\section{VIEGAS, CÍNTIA CAMILA LIBERALINO}

Doutora em Arquitetura e Urbanismo pelo Programa de Pós-Graduação em Arquitetura e Urbanismo da Universidade Federal do Rio Grande do Norte I 8cintiacamila8@gmail.com

\section{LIBERALINO, VICTOR}

Pós-Graduando na Residência em Tecnologia da Informação aplicada à Área Jurídica da Universidade Federal do Rio Grande do Norte | vliberalino@gmail.com

\section{SILVA, RODRIGO}

Graduando do Curso de Arquitetura e Urbanismo da Universidade Federal do Rio Grande do Norte | rdrg.silva94@gmail.com

\section{MARINHO, BÁRBARA RODRIGUES}

Graduanda do Curso de Arquitetura e Urbanismo da Universidade Federal do Rio Grande do Norte | barbara.rodm@gmail.com

\section{INTRODUÇÃO}

O conjunto de intervenções urbanas arquitetônicas denominado "Ribeira Conectada", apresentado ao concurso BID URBAN LAB Natal 2017, em sua primeira versão brasileira, teve os objetivos de promover vitalidade, habitabilidade e ambiência carregada de historicidade ao segundo bairro mais antigo de Natal, que é a capital do Rio Grande do Norte. O conceito da proposta remete a uma rede que articula princípios da conservação integrada do patrimônio cultural e das cidades inteligentes em favor de uma sustentabilidade socioambiental do bairro.

A Ribeira, lugar que outrora foi um dos principais cenários de vivências culturais, políticas e sociais de Natal, abrigou no período da Segunda Guerra Mundial diversos estabelecimentos comerciais e de serviços como hotéis, bares, bordéis, cinemas e clubes. A partir da segunda metade do século XX, momento em que 0 comércio foi deslocado para outras áreas da cidade, o local passa gradativamente a sofrer um processo de esvaziamento, abandono e degradação do ambiente construído, criando uma imagem ambiental do bairro 
muito associada a um local abandonado e inseguro. Hoje, uma porção da Ribeira está inserida em poligonais de tombamento e entorno do Sítio Histórico de Natal por concentrar edificações de expressão, com alguns remanescentes da arquitetura modesta que constituem os objetos de arte da cidade "caracterizadores do tecido urbano em que se encontram, contando parte significativa da sua história, merecendo por isso serem preservados" (BRASIL.IPHAN. Processo de Tombamento $n^{\circ}$ 1558-T-08, vol. I, fl. 11, 2010). O desafio da proposta, portanto, foi conciliar passado, presente e futuro valorizando as potencialidades da região, como a diversidade de modais de transporte existentes e sua vocação como polo cultural e boêmio da cidade, além de atrair novas dinâmicas e demandas da sociedade contemporânea.

\section{DESENVOLVIMENTO DA PROPOSTA}

Com base nas questões apresentadas, foram identificadas três abordagens principais a serem enfrentadas: (1) A degradação e pouca exploração turística do patrimônio histórico-cultural do bairro; (2) A carência de habitações, comércios e serviços de primeira necessidade, que contribuem para amplificar a sensação de insegurança na área; e (3) A falta de integração local com a cidade de forma geral, ausência de recursos tecnológicos que favoreçam a comunicação e a mobilidade, distanciamento visual e social dos habitantes de Natal com o Rio Potengi e problemas de acessibilidade. As referidas problemáticas motivaram as seguintes estratégias projetuais, respectivamente: (1) Reabilitação; (2) Habitabilidade; (3) Conectividade.

Com o propósito de responder a essa reflexão, envolvendo as problemáticas e as potencialidades da área, o conceito de Rede, como uma estrutura que interconecta os principais pontos da Ribeira, foi resgatado a fim de associar os mencionados pressupostos da conservação integrada e das cidades inteligentes em prol da criação de uma sustentabilidade socioambiental para a Ribeira.

A ideia geral da "Conservação Integrada" $(\mathrm{Cl})$ está na integração entre a preservação do patrimônio cultural e o planejamento urbano, entendido na sua dimensão mais ampla (CASTRIOTA et. al., 2010), sobretudo com os novos paradigmas do planejamento que apontam frequentemente para o desenvolvimento sustentável das cidades (ZANCHETI, 2007). Caracteriza-se pelos princípios do planejamento e gestão de áreas urbanas de interesse patrimonial de modo integrado nos aspectos econômico, político, cultural, ambiental e físicoespacial; pelo desenvolvimento que privilegia a conservação do patrimônio cultural em processos de transformação urbana; pelo entendimento de conservação como uma forma especial do processo de transformação urbana que procura manter no tempo (intergerações) a integridade e a autenticidade do patrimônio cultural e pela busca do desenvolvimento sustentável, inserindo a conservação do patrimôniocultural urbano, como um ativo que agrega valor em todas as dimensões do desenvolvimento urbano (ZANCHETI, 2008).

A respeito do sentido de Cidade Inteligente adotado neste trabalho, podemos compreendê-la como uma cidade que possui uma administração pública integrada e transparente, adotando elementos e procedimentos que aumentem a governança, a otimização de alocação de recursos e o envolvimento da sociedade civil nos processos de administração, geração, controle e manipulação de dados, de maneira a melhorar os serviços na região. Para se alcançar esses objetivos, a Tecnologia da Informação e Comunicação (TIC) e a engenharia trazem elementos fundamentais em contexto contemporâneo. Ashton (2009) propôs em 1999 o termo Internet of Things ( loT - Internet das Coisas) para conceituar a ideia de interação entre diferentes objetos físicos por meio de uma rede de comunicação sem a obrigatória necessidade da presença de um ser humano para que ela ocorra. Por meio dessa rede, é possível que elementos de mobiliário urbano convencionais como lixeiras, postes, paradas de ônibus, entre outros, sejam equipados com Internet, sensores, difusores, chips, monitores, softwares, etc. e se comuniquem com centros de dados e operações da cidade e outros aparelhos conectados na rede, levando à integração entre elementos urbanos, dispositivos eletrônicos, população e governo. Nesse cenário, o termo Cidade Inteligente se une ao conceito de Internet das Coisas objetivando o desenvolvimento de uma cidade de forma otimizada, transparente e sustentável, que se adequa ao esperado crescimento da população urbana e a difusão de tecnologias digitais.

Retomando a proposta em questão e diante destes conceitos, pretendemos, portanto, integrar o planejamento, a gestão e a ação da cidade contemporânea ao ambiente patrimonial e à tecnologia da informação, levando em consideração os aspectos econômicos, culturais, ambientais e físico-espaciais. Buscamos adotar uma linguagem contemporânea para a arquitetura, articulando tradições, cotidianos e perspectivas, em um mesmo contexto socioespacial. Ao materializar os princípios anunciados em projetos arquitetônicos e urbanísticos para a Ribeira, foram estabelecidos oitos eixos de intervenções projetuais (Figura 1). 
Figura 1: Esquema representando os três conceitos trabalhados na proposta e os oito eixos de intervenção.

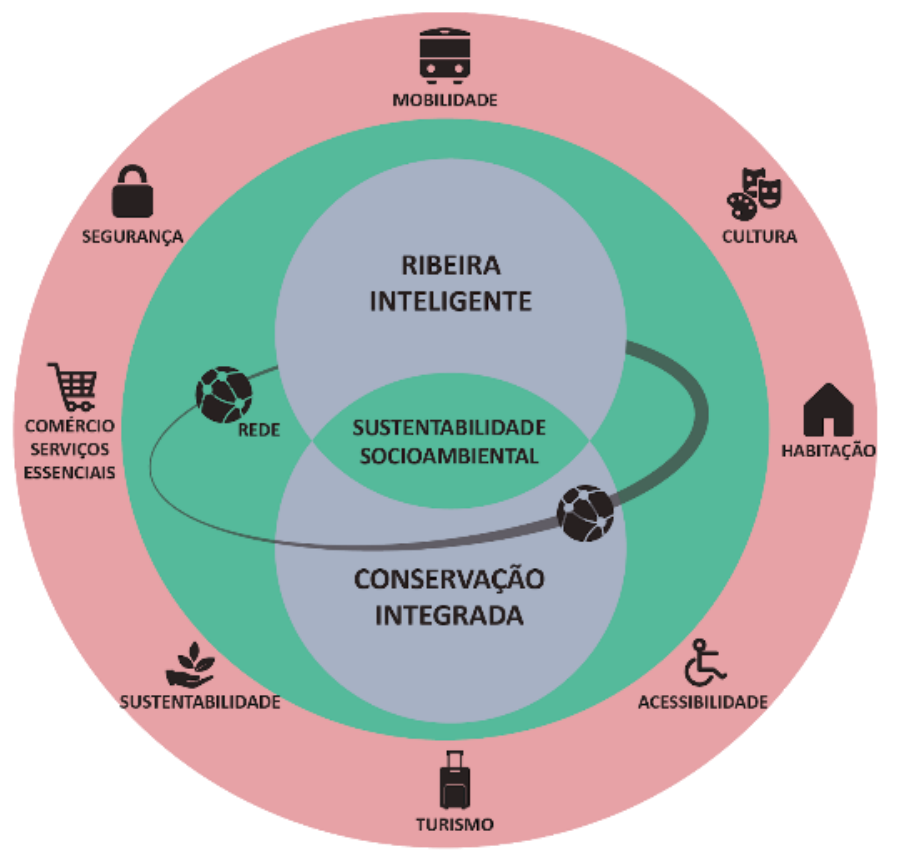

Fonte: Equipe Ribeira Conectada (2017).

O primeiro eixo de intervenção denomina-se Mobilidade e visa contemplar os diversos tipos de modais de forma integrada, priorizando o pedestre, que será assistido por rotas peatonais no núcleo inicial do bairro, sem extinguir o fluxo de automóveis. O segundo, de Habitação, pretende ampliar o número de moradores no bairro, especialmente nas áreas antigas, destinando imóveis desocupados a hostel e imóveis de uso misto, tornando as ruas ativas em todos os períodos do dia e implementando unidades habitacionais térreas nas áreas periféricas do perímetro de intervenção. O terceiro eixo, de Comércios e Serviços Essenciais, objetiva aumentar a habitabilidade da região, com comércios e serviços de primeira necessidade para os moradores e trabalhadores do bairro (numa escala caminhável). O quarto refere-se ao Turismo e visa incentivar o turismo cultural, atividade importante para a sustentabilidade socioambiental e econômica da área, atraindo turistas que desembarcam no porto a conhecer e desfrutar o local. O quinto eixo de intervenção, da Segurança, propõe ocupar os edifícios vazios com usos diversos, melhorar a iluminação das vias e demais espaços públicos e estabelecer controle de tráfego e monitoramento das ruas através de câmeras e dispositivos. $O$ sexto eixo denomina-se Cultura e busca evidenciar o legado cultural do lugar, promover ações de educação patrimonial, definir roteiros culturais e divulgá-las em aplicativos móveis. Além disso, aproveitar o caráter boêmio e de atividades culturais já existentes, utilizando estruturas subaproveitadas ou desocupadas com a prática de esportes e movimentos artísticos. O sétimo eixo, da Sustentabilidade, visa garantir um ambiente mais agradável aos usuários, no que concerne a qualidade paisagística - integrando melhor o bairro com o Rio Potengi - e se preocupando com o conforto termo-acústico. Além disso, deve-se buscar que a população tenha uma maior autonomia alimentar e que exista uma gestão adequada dos seus resíduos e drenagem de águas pluviais. Por fim, o oitavo eixo denomina-se Acessibilidade e Comunicação Visual e pretende garantir o livre acesso de pessoas com deficiência ou mobilidade reduzida a área. Usar a comunicação visual e wayfinding para sinalizar e indicar o patrimônio histórico e arquitetônico pelo meio de recursos escritos e sonoros, além da demarcação de piso que diferencie a poligonal de tombamento das demais áreas, aumentando a legibilidade local.

\section{SOLUÇÕES PROJETUAIS}

Desse modo, conforme já dito, o projeto desenvolvido pela equipe Ribeira Conectada visa conciliar passado, presente e futuro, articulando, por meio do conceito de REDE adotado, princípios da Conservação Integrada e das Cidades Inteligentes (unindo-se ao o conceito de Internet das Coisas) em favor de uma Sustentabilidade Socioambiental. Nesse sentido, pretende integrar o planejamento e a gestão da fração antiga de Natal com as necessidades e a dinâmica da vida contemporânea encontrada nos bairros mais recentes da cidade, onde ocorrem maiores investimentos, sem desconsiderar as qualidades ambientais, patrimoniais e culturais do universo de intervenção. 
Inicialmente, a proposta contempla o referido conceito de Internet das Coisas, que consiste no uso de uma infraestrutura de conexão que permita a instalação de uma rede de objetos e de construções dotados de tecnologia capaz de transferir dados úteis às pessoas. Nesse sentido, a Ribeira Conectada, que também articula estratégias de incentivo à participação social na gestão da região, configura-se como um projeto piloto de Cidade Inteligente em Natal. A proposta adota equipamentos tecnológicos/digitais, que fazem parte de um plano de modernização de infraestrutura da região, que contempla a substituição de instalações elétricas, atualmente aéreas, por subterrâneas, contribuindo não somente para tornar a infraestrutura local mais segura, como também para promover a despoluição visual e resgatar a ambiência histórica do lugar. A rede de fibra óptica Giga Natal será interligada à Ribeira, permitindo a instalação de postes equipados com LED, difusores wireless, sensores de presença e botões de pânico e câmeras de segurança estrategicamente posicionadas a serem conectadas ao Centro Integrado de Operações de Segurança Pública (CIOSP), auxiliando a segurança local. O acesso $\mathrm{Wi}-\mathrm{Fi}$ em locais públicos também compõe o plano. O projeto ainda contempla a remodelagem de pontos para paradas de ônibus na área de intervenção equipados com painéis solares, botões de pânico, luzes LED e telas contendo rotas e horários da rede de transporte público.

Com respeito aos usos do solo, a proposta visa diversificá-los com a ocupação de imóveis desocupados, com ênfase na promoção do uso habitacional, praticamente inexistente no bairro, mas com grande potencial. Desse modo, é recomendado o reuso desses edifícios sem uso para instalação de apartamentos e hospedagens, além de comércios, serviços de primeira necessidade que atendam a população local e turística, assim como estacionamentos para automóveis e bicicletas, atualmente escassos (Figura 2).

Figura 2: Plano geral de intervenções.

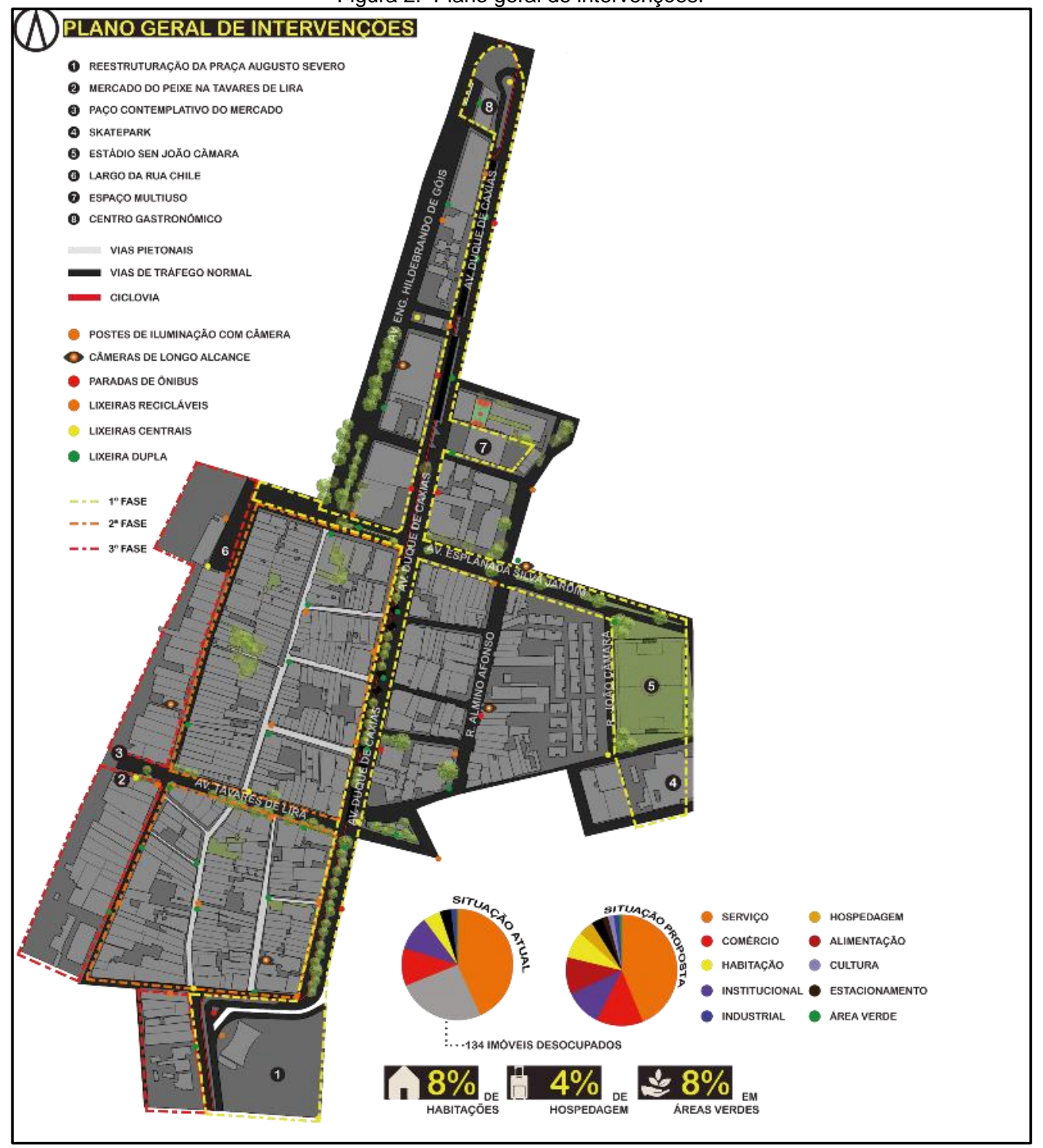

Fonte: Equipe Ribeira Conectada (2017). 
No Cais da Av. Tavares de Lira, é proposta a relocação e organização do mercado de peixe e da atividade pesqueira para os edifícios próximos, incluindo um mirante acessível em diferentes níveis de piso para promover uma maior abertura visual e física para o Rio Potengi (Figura 3).

Figura 3: Edifício reabilitado, que receberá novo mercado do peixe, junto com o mirante aberto

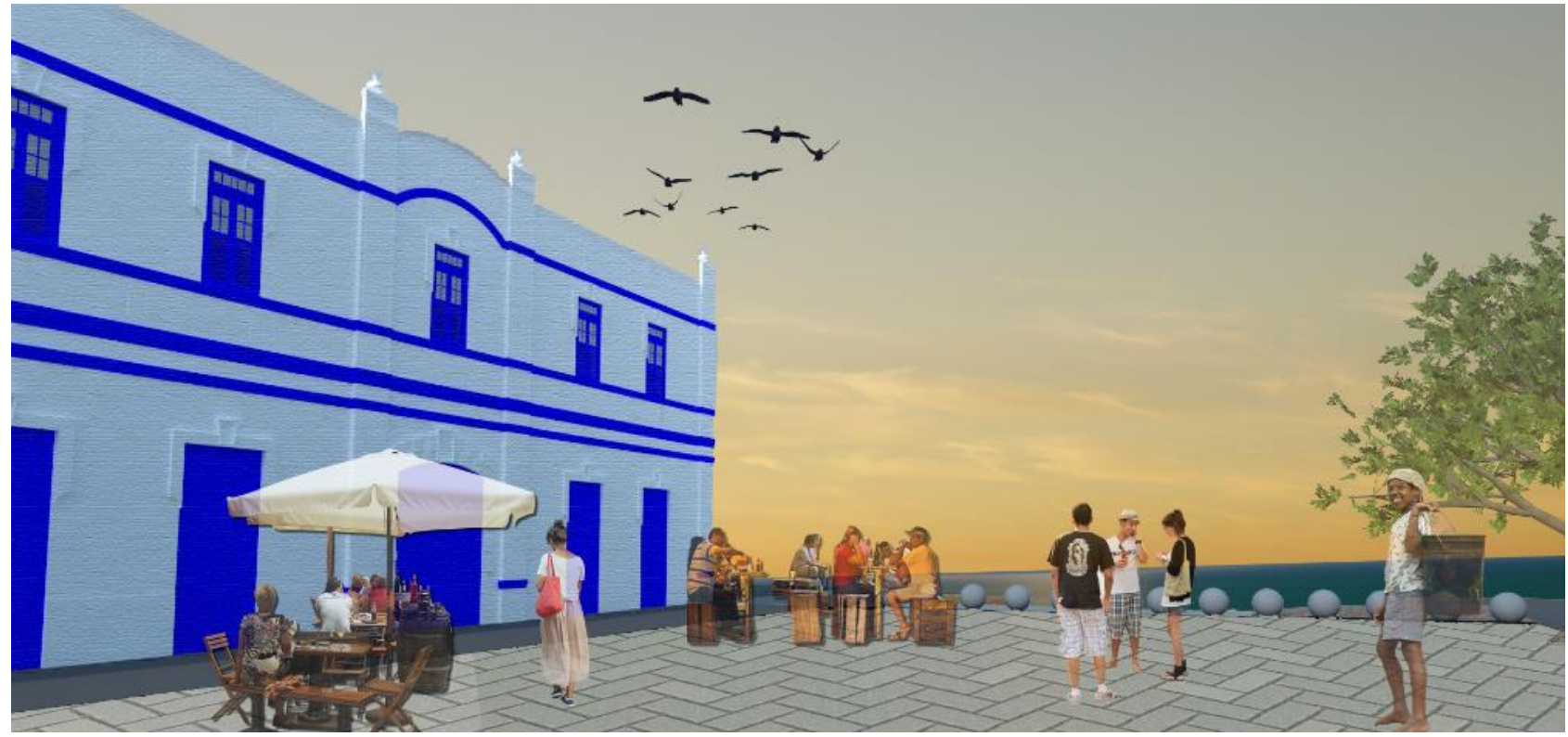

Fonte: Equipe Ribeira Conectada (2017).

Uma outra solução projetual consiste na criação de um Centro Gastronômico e Arena Multiuso. O Centro Gastronômico pretende ampliar e requalificar os usos existentes do entorno, potencializando a feira que já existe na região e o Mercado do Peixe das Rocas (Figura 4), enquanto a Arena Multiuso, por sua vez, foi pensada para abrigar atividades culturais e eventos locais (Figura 5). O reuso de galpões para abrigo destes programas visa promover a preservação das estruturas existentes no bairro e fortalecer a identidade de área portuária da cidade.

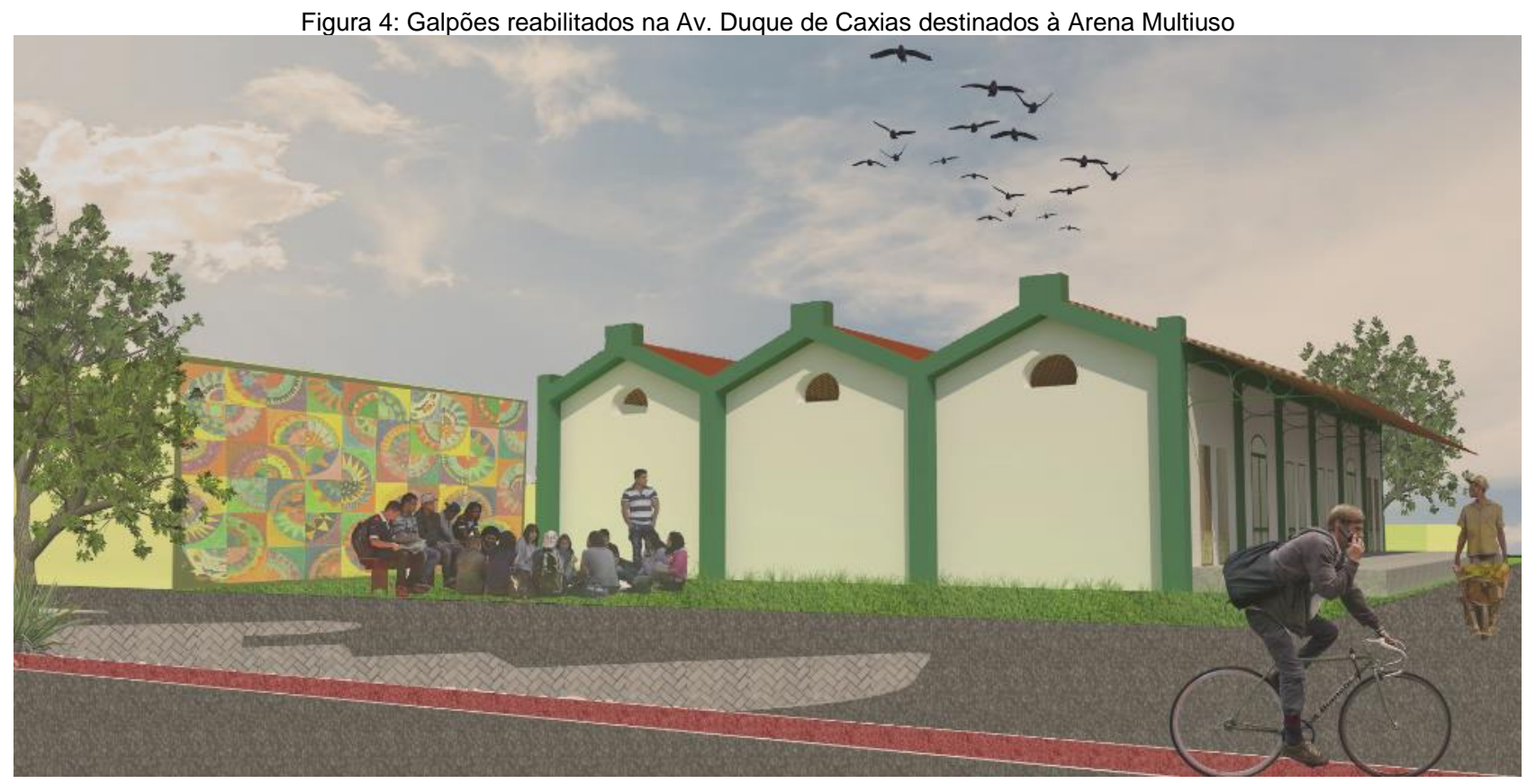

Fonte: Equipe Ribeira Conectada (2017). 
Figura 5: Galpões reabilitados na Av. Duque de Caxias destinados ao Centro Gastronômico.

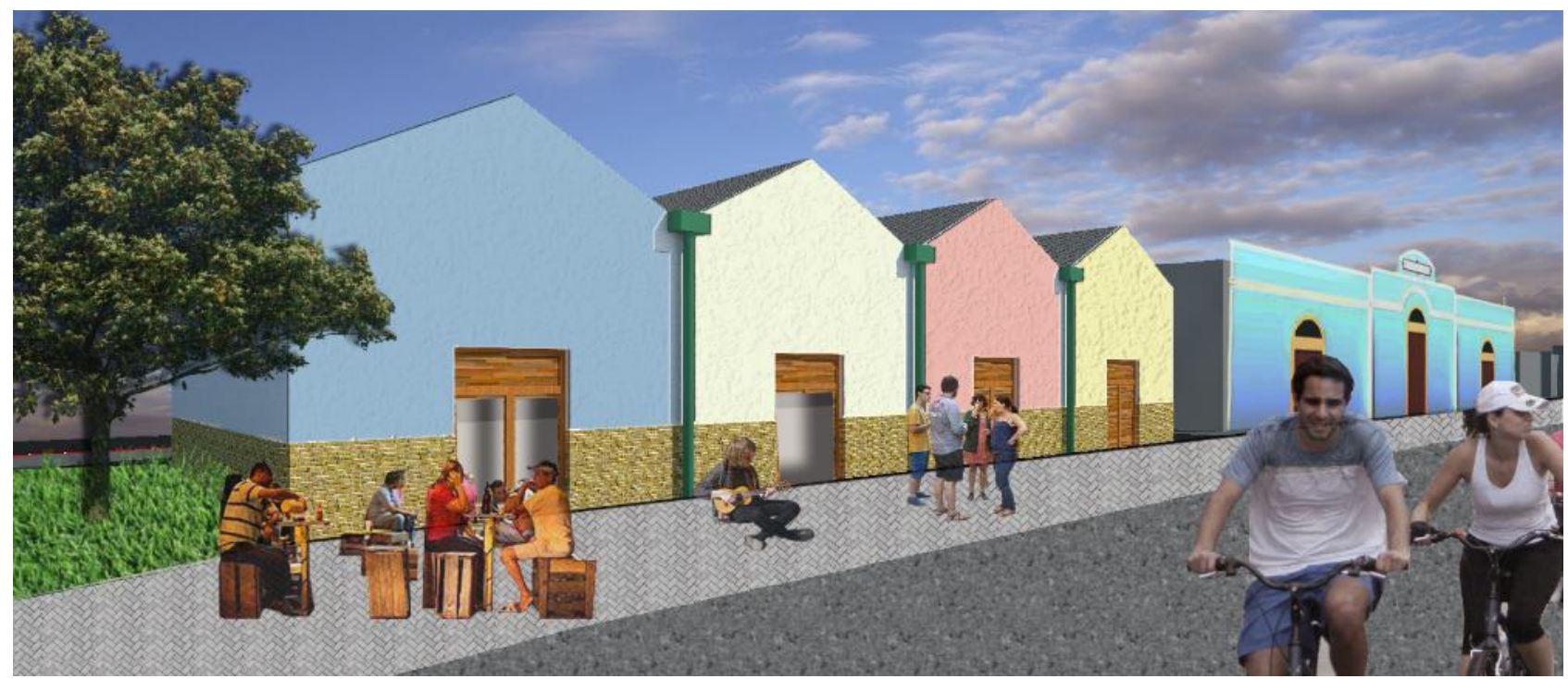

Fonte: Equipe Ribeira Conectada (2017).

$\mathrm{Na}$ Av. Duque de Caxias e Esplanada Silva Jardim, onde se encontram áridos canteiros centrais, foi pensada uma proposta paisagística com mobiliário urbano e infraestrutura para abrigar pedestres e ciclistas que desejem permanecer ou circular no local, de modo que essa estrutura viária possa interligar as praças existentes na poligonal de intervenção, ao mesmo tempo em que se configure como novos espaços livres públicos que promovam urbanidade e contribuam para a constituição de um sistema de espaços livres públicos (Figura 6).

Figura 6: Canteiro da Av. Duque de Caxias

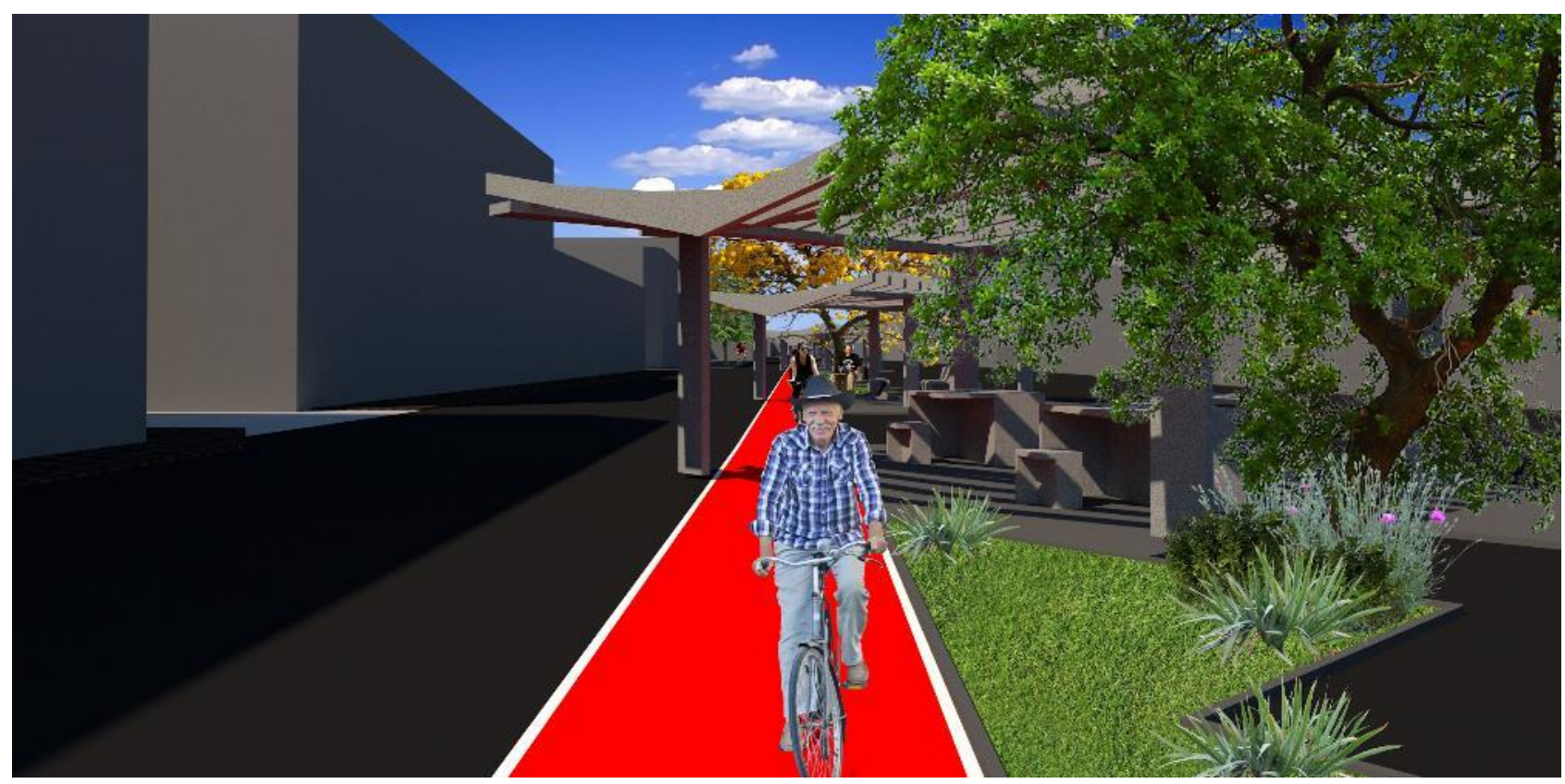

Fonte: Equipe Ribeira Conectada (2017).

Com respeito ao Mobiliário Urbano (Figura 7), a equipe propôs o uso do concreto, levando em consideração a capacidade de fabricação na região, a durabilidade, a economia e a fácil modulação. É composto por caramanchões feitos por entravamentos concorrentes de diferentes angulações, que criam movimento e proteção nos canteiros das Avenidas Duque de Caxias e Esplanada Silva Jardim. Para os pontos de parada de ônibus foram previstos mobiliários com proteção solar e assento, bem como com painel físico com os 
horários previstos para cada linha de ônibus. São, ainda, equipados com painel solar para captação de energia. As espreguiçadeiras estão colocadas sob alguns caramanchões, mas principalmente no paço contemplativo da Av. Tavares de Lira, onde é feito de maneira fluída, unindo vários módulos. Os bancos são formados por perfis simples e porticados encaixáveis, encontrados principalmente nas proximidades do Mercado do Peixe. As mesas de xadrez são formadas por peças únicas e que podem funcionar como mesas maiores quando dispostas lado a lado.

Figura 7: Mobiliário Urbano utilizado na proposta.

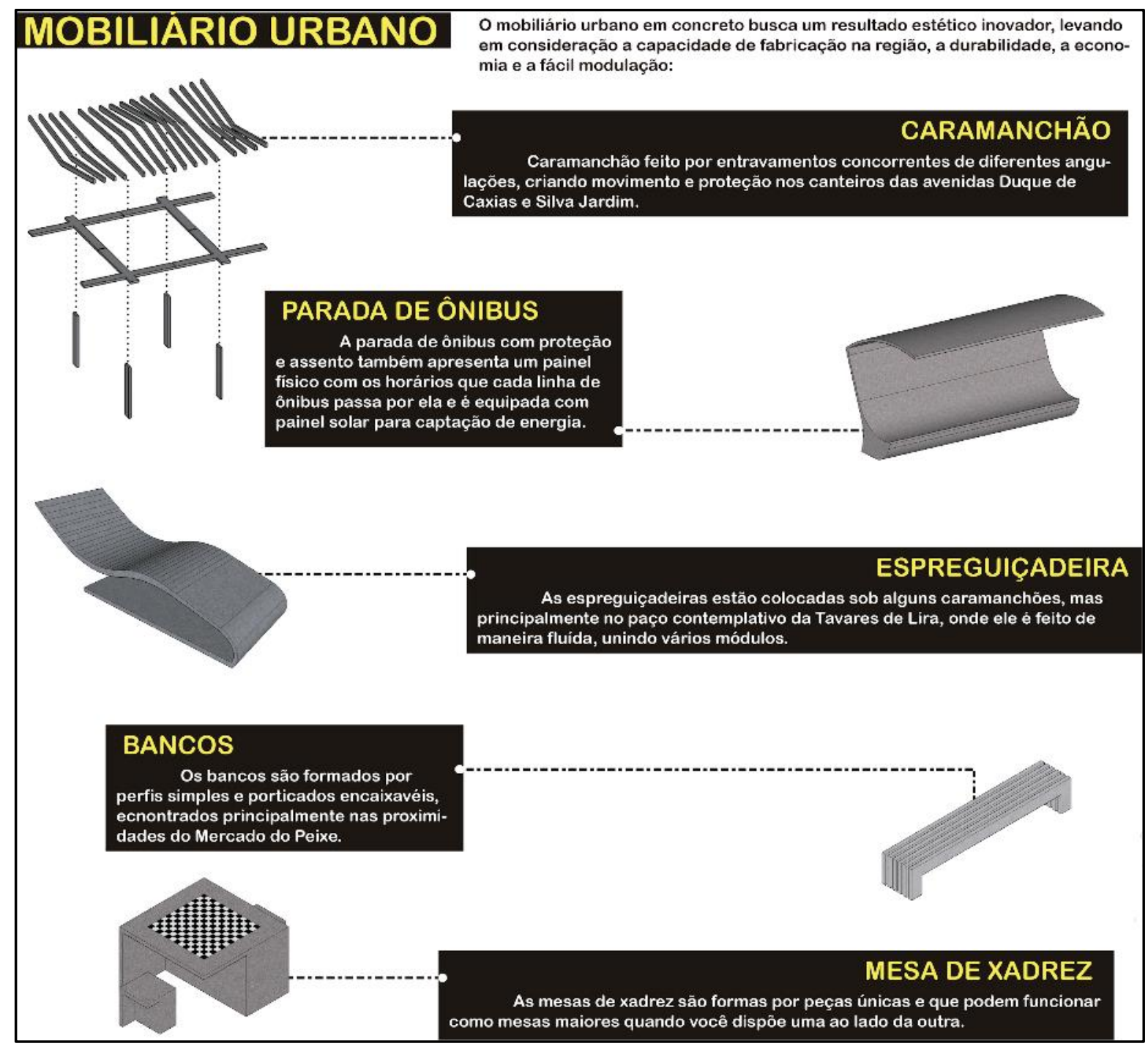

Fonte: Equipe Ribeira Conectada (2017).

\section{CONSIDERAÇÕES FINAIS}

Entre as propostas apresentadas pela equipe Ribeira Conectada destacamos a preocupação principal com a reabilitação do patrimônio material e imaterial do bairro, composto por edificações de valor patrimonial expressivo, práticas pesqueiras e manifestações culturais cotidianas locais. Ressaltamos também a importância de uma equipe multidisciplinar ${ }^{1}$ de estudantes de graduação, pós-graduandos e professores das áreas de arquitetura e urbanismo, engenharias civil, elétrica, ambiental e de computação, que gerou olhares diversos tanto para a leitura técnica da área de intervenção, quanto para os próprios projetos arquitetônicos e urbanos.

Sabemos que os desafios projetuais para a área de intervenção são amplos e é imprescindível uma gestão patrimonial participativa para reverter efetivamente o quadro de degradação e abandono do ambiente construído, ainda que reconheçamos a dinâmica cotidiana atual do bairro, que deve ser valorizada e promovida.

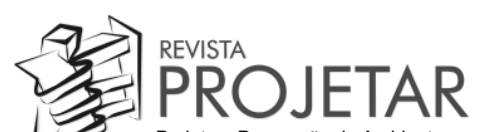


A oportunidade de participação no Concurso BID URBAN LAB Natal 2017 renovou expectativas de ver a Ribeira mais viva e conectada. Observamos que iniciativas com o intuito de sistematizar análises e propostas para esta área central de Natal, como a promovida por este periódico, são muito pertinentes, pois corroboram para subsidiar políticas públicas abrangentes e efetivas no sentido de uma reabilitação legítima e eficiente para o bairro.

\section{REFERÊNCIAS}

ASHTON, K. That 'internet of things' thing. RFID journal, v. 22, n. 7, p. 97-114, 2009.

BRASIL. IPHAN. Centro Histórico de Natal, Processo de Tombamento no 1.558-T-08, v. 1, 2 e 3. Natal: IPHAN, 2010.

CASTRIOTA, L. B.; ARAÚJO, G. M.; CARDOZO, K.; SOUSA, V. P. PAC Cidades Históricas - oportunidade para a conservação integrada? Locus: revista de história, Juiz de Fora, v. 16, n. 2, p. 93-117, 2010.

ZANCHETI, S. M. Conservação urbana: textos do momento. Olinda: CECI, 2008.

ZANCHETI, S. M. Gestão da conservação e desenvolvimento urbano sustentável no Brasil: propostas para uma agenda. Olinda: CECI, 2007.

\section{NOTAS}

${ }^{1}$ Equipe Ribeira Conectada, inscrita no Concurso BID URBAN LAB Natal 2017:

HEITOR DE ANDRADE SILVA - Professor do Departamento de Arquitetura, do Programa de Pós-Graduação em Arquitetura e Urbanismo e Programa de Pós-Graduação em Arquitetura, Projeto e Meio Ambiente da Universidade Federal do Rio Grande do Norte

REYMARD SÁVIO SAMPAIO MELO - Professor do Departamento de Engenharia Civil e do Programa de Pós-Graduação em Engenharia Civil da Universidade Federal do Rio Grande do Norte

VICTOR LIBERALINO - Pós-Graduando na Residência em Tecnologia da Informação aplicada à Área Jurídica da Universidade Federal do Rio Grande do Norte

RODRIGO SILVA - Graduando do Curso de Arquitetura e Urbanismo da Universidade Federal do Rio Grande do Norte

BÁRBARA RODRIGUES MARINHO - Graduanda do Curso de Arquitetura e Urbanismo da Universidade Federal do Rio Grande do Norte

DANIEL LOPES DE LUNA FREIRE - Graduando do Curso de Arquitetura e Urbanismo da Universidade Federal do Rio Grande do Norte DIMITRI FERNANDES CAMILO DE LIMA - Graduando do Curso de Engenharia Elétrica da Universidade Federal do Rio Grande do Norte

VINÍCIUS DE OLIVEIRA MARRAFA - Engenheiro Ambiental graduado pela Universidade Federal do Rio Grande do Norte

Com a colaboração de CÍNTIA CAMILA LIBERALINO VIEGAS - Doutora em Arquitetura e Urbanismo pelo Programa de Pós-Graduação em Arquitetura e Urbanismo da Universidade Federal do Rio Grande do Norte

NOTA DO EDITOR (*) O conteúdo do artigo e as imagens nele publicadas são de responsabilidade do(s) autor(es). 